\title{
Effects of genetic variability on running performance in professional runners
}

\author{
Aatik Arsh ${ }^{1}$, Haider Darain ${ }^{2}$, Abdulhameed Al-kitani ${ }^{3}$
}

\author{
Submitted: \\ July 16, 2020 \\ Accepted: \\ August 18, 2020

\section{Author Information \\ ${ }^{1,2}$ Khyber Medical University} \\ ${ }^{3}$ Ministry of Sports Oman
}

\section{Corresponding Author}

Aatik Arsh

Lecturer Khyber Medical University

Institute of Physical Medicine and Rehabilitation

Email: aatikarshkmu@yahoo.com

\begin{abstract}
Introduction: With the recent advancement in the field of genetics, researchers and general public are interested to know the effects of genetic variability on human body. A variety of studies can be found literature regarding the genetic variabilities on human body, however, there is a scarcity of data regarding systematic review on the topic. This review was conducted in order to systematically review the available literature on the effects of genetic variability on running performance in professional runners.

Material \& Methods: A systematic review was conducted according to PRISMA guidelines. The literature search was performed in different databases using the terms genes OR genetic (variation, variability, polymorphism) OR genomics AND running (performance, status, success) OR elite runners OR competitive running. Research articles published in English language from inception of medical literature to August 2019 that reported the effects of genetic variability on running performance were included. Those studies were excluded which reported association of gene mutations with genetic disorders. Reviews, commentaries, letter to editors and conference papers were excluded.

Results: Out of total 8 included studies, 5 were case control and 3 were cohort studies. Six articles showed association between genetic variability and running performance while 2 reported no association between genetic variability and running performance in professional runners. Three studies investigated 'I' and 'D' allele of angiotensin-converting enzyme (ACE) gene, out of which two studies found association between 'D' allele of 'ACE' gene and running performance. Besides ACE, the included studies reported association between running performance and 'C' allele of aquaporin 1, Pro582 C allele of rs11549465 \& 'A' allele of rs17099207 of HIF1A gene, bradykinin receptor B2, adrenergic receptor beta 2 \& adenosine monophosphate deaminase 1 and Titin gene.

Conclusion: Genes such as 'ACE', 'HIF1A', aquaporin '1' and Titin may be associated with running performance in professional runners, however, there is limited evidence regarding it as only few articles have been published on this topic. Majority of the published articles are case control studies which clearly indicate a demand for conducting high quality research in this area.

Key Words: Athlete, Elite, Genes, Performance, Running, Variation
\end{abstract}

The authors declared no conflict of interest and agreed to be accountable for all aspects of the work in ensuring that questions related to the accuracy or integrity of any part of the work are appropriately investigated and resolved.All authors contributed substantially to the planning of review, data collection and write-up of the systematic review.

This review article may be cited as:Arsh A, Darain H, Al-kitani A. Effects of genetic variability on running performance in professional runners. Rehman J Health Sci. $2020 ; 2(1) .2-5$

\section{INTRODUCTION}

With the recent advancement in the field of genetics, researchers and general public are interested to know the effects of genetic variability on human body. ${ }^{1}$ In the past two decades, hundreds of genetic variations have been reported which can have effect on human physical performance. ${ }^{2}$ Because physical performance is necessary for athletic activities that's why researchers and sport communities pay much attention to determine the association of genetic factors with athletes' status. ${ }^{3}$

Just like other athletic activities, running performance predominantly depends on runners' physique and other physiological characteristics which in turn depend on genetic makeup of the athlete. Some genes such as angiotensin-converting enzyme (ACE) gene, are consistently reported in the literature to be associated with physical performance. ${ }^{4-6}$ The genetic testing enables the sporting community to predict athletic performance on the basis of the genetic makeup of the athlete. ${ }^{1}$

Despite the fact that quite a few studies have been conducted to report the association of genetic factors and physical performance, still, literature regarding the effects of genetic variation on running performance is scarce. Therefore, the current study was designed to systematically review the available literature on the effects of genetic variability on running performance in professional

\section{MATERIALS \& METHODS}

A systematic review was conducted according to Preferred Reporting Items for Systematic Reviews and Meta-analysis (PRISMA) guidelines. Literature search was performed in databases MEDLINE, AMED, EMBASE, HMIC, BNI, PsycInfo, CINAHL (EBSCO), and HEALTH BUSINESS ELITE in September 2019. The literature search was performed using the terms genes OR genetic (variation, variability, polymorphism) OR genomics AND running (performance, status, success) OR elite runners OR competitive running. Search terms were combined using Boolean logic. Truncations were used where appropriate. Systematic reference list scanning was conducted to find out additional articles. Search results were imported into reference manager Endnote X7 in order to remove the duplicates. After 
duplicate removal, two reviewers independently screened the titles and abstracts of the studies and divided the articles into 'relevant' and 'irrelevant' categories according to inclusion and exclusion criteria. All discrepancies were resolved by consensus meeting and discussion. Research articles published from inception of medical literature to August 2019 that reported the effects of genetic variability on running performance were included. Only peerreviewed articles in English language were included. Those studies were excluded which reported association of gene mutations with genetic disorders. Similarly, views, commentaries, letter to editors and conference papers were excluded. From each included study, participants characteristics, genes under investigation and primary findings were extracted.

\section{RESULTS}

Initial searches identified 289 research articles. Following removal of the duplicates, 215 studies were left. Of these, 24 were excluded because they were published in languages other than English. Titles and abstracts of the remaining 191 articles were screened, and 183 were excluded because they did not fulfill the eligibility criteria. Finally, 8 studies were included in the current systematic review. Summary of the included studies is presented in table I.
Out of total 8 studies, 5 were case control ${ }^{7-11}$ and 3 were cohort studies. ${ }^{12-14}$ Six articles determine association between genetic variability and running performance ${ }^{7-10,12,13}$ while 2 reported no significant association between genetic variability and running performance in professional runners. ${ }^{11,}{ }^{14}$ Three studies investigated 'I' and 'D' allele of angiotensin-converting enzyme (ACE) gene ${ }^{7,10,14}$, out of which two found association between 'D' allele of ACE gene and running performance ${ }^{7,10}$ while one study reported no association of ACE gene with running performance. $^{14}$

The other genes investigated in the included studies were aquaporin '1' 'C' \& 'G' allele, hypoxia-inducible factor 1-alpha (HIF1A) gene, Bradykinin receptor B2, adrenergic receptor beta 2, adenosine monophosphate deaminase 1, alpha-actinin-3, peroxisome proliferator activated receptor alpha, adrenergic receptor alpha 2A rs553668 C\&T allell, alpha-actinin-3 and Titin gene. ${ }^{8,9,11-14}$ The studies reported association between running performance and 'C' allele of aquaporin $1^{8}$, Pro582 C allele of rs11549465 \& 'A' allele of rs17099207 of HIF1A gene', bradykinin receptor $\mathrm{B} 2$, adrenergic receptor beta 2 \& adenosine monophosphate deaminase 112 and Titin rs10497520. ${ }^{12}$

Table 1: details of the studies included in the review

Study and participant information
Amir et al. conducted a case control
study in 2007 in which 79 professional
runners, 42 athletes and 247 controls
participated.
Martinez et al. conducted a case control
study in 2009 in which 1177 professiona
runners participated.
Döring et al. conducted a case control
study in 2010 in which 316 professional
athletes, out of which 39 were runner
participated. There were 304 controls.
Tobina et al. conducted a case control
study in 2010 in which 73 professional
runners and 335 controls from general
population participated.

Tsianos et al. conducted a cohort study in 2010 in which 438 professional runners participated.

Sawczuk et al. conducted a case control study in 2013 in which 123 athletes, out of which 12 were professional athletes participated. There were 228 controls.

Stebbings et al. conducted a cohort study in 2018 in which 141 professional runners and 137 controls participated.

Papadimitriou et al. conducted a cohort study in 2018 in which 698 professional runners participated.
Genes and SNPs under investigation

Genes and SNPs under investigation

Insertion (I) allele and deletion (D) allele of angiotensin-converting enzyme gene rs4646994

aquaporin 1 rs1049305 C\&G allele

Hypoxia-inducible factor 1-alpha gene

The authors reported that Pro582 C allele of rs11549465 and A allele of rs 17099207 were related to running performance. These SNPs were significantly of higher percentage in professional runners as compared to controls.

Insertion (I) allele and deletion (D) allele of angiotensin-converting enzyme gene rs4646994

They concluded that $\mathrm{D}$ allele was responsible for fast running however angiotensinconverting enzyme gene I \& D frequencey was not too mcuh higher in professional runners.

Bradykinin receptor $\mathrm{B} 2$, adrenergic receptor beta 2 , adenosine monophosphate deaminase 1, alphaactinin-3, peroxisome proliferator activated receptor alpha

adrenergic receptor alpha $2 \mathrm{~A}$ rs553668 C $\&$ T allell

alpha-actinin-3 R577X, Insertion (I) allele and deletion (D) allele of angiotensin-converting enzyme gene
The authors failed to find association between running performance and genes under investigation.

Titin is reported to be associated with faster running performance dut to its effects on anatomy and physiology of muscle fascicle

Bradykinin receptor $\mathrm{B} 2$, adrenergic receptor beta 2 and adenosine monophosphate deaminase 1 were found to be associated with running performance.

The authors failed to find association between running performance and genes under investigation. 


\section{DISCUSSION}

In the modern era of advancement and technology, genetic studies have received robust attention. A lot has been written and published about genomes and a huge amount of literature has been produced in the last two decades. ${ }^{15}$ Many mutations have been identified and many genetic disorders can be diagnosed on the basis of gene analysis. ${ }^{16}$ Besides disease identification, researchers investigated the effects of different gene sequencing on normal morphology and physiology. ${ }^{13}$ A huge bulk of literature is produced to discuss the effects of genetic variability on human performance. Despite all this, there is not enough evidence to support the argument that genetic variations contribute to running performance in professional runners. ${ }^{17}$ Therefore, the current systematic review was carried out to assimilate the available literature regarding the effects of genetic variability on running performance in professional runners.

The results of current study revealed that out of total 8 included studies, 6 studies concluded that different genes and SNP's are associated with running performance ${ }^{7-10,12,13}$ while two studies failed to show association between genes under investigation and running performance in professional runners. ${ }^{11,}{ }^{14}$ Studies in humans and in other animals have revealed that a large number of genes are responsible for physical performance. ${ }^{18}$ The development of molecular genetics analyses enable the researcher to identify those specific genes which enhance the physical performance. Many high quality researches in the form of systematic reviews and meta-analysis provide evidence for the assumption that some genes are responsible for better performance in sports. ${ }^{19,} 20$ Because there is lack of high quality evidence regarding association of specific genes and running performance, that is the reason that many investigators are searching to determine whether those genes which enhance the physical performance also increases the running performance in professional runners. ${ }^{17}$

ACE gene is the most commonly discussed gene in literature which is supposed to be responsible for better athletic performance. ${ }^{1,21}$ Results of the current study revealed that two studies supported the argument that it is associated with running performance in professional runners. Though there are some studies which reported that the ACE gene effects on physical performance is debatable, ${ }^{22-24}$ however, many researchers believe it to be the utmost gene involved in physical performance. ${ }^{8-10,13}$ Besides ACE, other genes such as aquaporin 1, HIF1A gene and Titin gene are reported to be associated with physical performance. ${ }^{1,3,5}$ In accordance with the results of previous studies, the current systematic review also reported that these genes are responsible for better running performance in professional runners.

Despite the fact that current review assimilate published literature regarding the effects of genetic variability on running performance in professional runners, still, it has some limitations. Protocols of the current review were not registered and due to scarcity of literature about the effects of genetic variability on running performance, the current review only included 8 studies. It is recommended that large clinical trials and multi-centered prospective cohort studies should be conducted to truly determine the effects of genetic variability on running performance in professional runners.

\section{CONCLUSION}

Genetic variations exist in professional runners and general population. Certain genes such as ACE, HIF1A, aquaporin 1 and Titin genes may be associated with running performance in professional runners, however, there is limited evidence regarding it, as only few articles have been published on this topic. Majority of the published articles are case control studies which clearly indicate for a demand for conducting high quality research in this area. 


\section{REFERENCES}

1. Guth LM, Roth SM. Genetic influence on athletic performance. Curr Opin Pediatr 2013;25(6): 653-658.

2. Macarthur DG, North KN. Genes and human elite athletic performance. Hum Genet 2005;116: 331-339.

3. Bray MS, Hagberg JM, Pérusse L, et al. The human gene map for performance and health-related fitness phenotypes: the 2006-2007 update. Med Sci Sports Exerc 2009; 41(1):35-73.

4. Ahmetov I.I., Druzhevskaya A.M., Astratenkova I.V., Popov D.V.,Vinogradova O.L., Rogozkin V.A. The ACTN3 R577X polymorphism in Russian endurance athletes. Br. J. Sports Med. 2010;44:649-652.

5. Yang N., Garton F., North K. alphaactinin-3 and performance. Med Sport Sci 2009; 54:88-101.

6. Oh SD.The distribution of I/D polymorphism in the ACE gene among Korean male elite athletes. J Sports Med Phys Fitness 2007;47: 250-254.

7. Amir, O., Amir, R., Yamin, C., Attias, E., Eynon, N., Sagiv, M., Sagiv, M. and Meckel,Y. The ACE deletion allele is associated with Israeli elite endurance athletes. Experimental Physiology 2007;92(5):881886.

8. Martinez, J.L., Carrion, A., Florian, M.E., Martin, J.A., Lopez-Taylor, J.R., Fahey, T.D. and Rivera, M.A. Aquaporin-1 Gene Dna Variation Predicts Performance in Hispanic Marathon Runners. Medicina Sportiva 2009;13(4):251-255.

9. Döring, F., Onur, S., Fischer, A., Boulay, M.R., Pérusse, L., Rankinen,T., Rauramaa, R., Wolfarth, B. and Bouchard, C. A common haplotype and the Pro582Ser polymorphism of the hypoxiainducible factor-1 (HIF1A) gene in elite endurance athletes. Journal of Applied Physiology 2010;108(6):497-500.

10. Tobina, T., Michishita, R., Yamasawa, F. Zhang, B., Sasaki, H., Tanaka,H., Saku, K. and Kiyonaga, A. Association between the angiotensin l-converting enzyme gene insertion/deletion polymorphism and endurance running speed in Japanese runners. The Journal of Physiological Sciences 2010;60(5):325-330.

11. Sawczuk, M., Maciejewska-Karlowska, A and Cieszczyk, P. A single nucleotide polymorphism rs553668 in the ADRA2A gene and the status of Polish elite endurance athletes. Trends in Sport Science 2013;20(1):30-35.

12. Tsianos, G.I., Evangelou, E., Boot, A., Carola Zillikens, M., van Meurs, J.B., Uitterlinden, A.G. and loannidis, J.P. Associations of polymorphisms of eight muscle-or metabolism-related genes with performance in Mount Olympus marathon runners. Journal of Applied Physiology 2010;108(3):567-574.

13. Stebbings, G.K., Williams, A.G., Herbert, A.J., Lockey, S.J., Heffernan, S.M., Erskine R.M., Morse, C.I. and Day, S.H. (2018) TTN genotype is associated with fascicle length and marathon running performance. Scandinavian Journal of Medicine and Science in Sports 2018;28(2):400-406.

14. Papadimitriou, I. D., Lockey, S. J., Voisin, S., Herbert, A. J., Garton, F., Houweling, P.J. Cieszczyk, P., Maciejewska-Skrendo, A. Sawczuk, M., Massidda, M. and Calò, C. M No association between ACTN3 R577X and ACE I/D polymorphisms and endurance running times in 698 Caucasian athletes. BMC Genomics 2018;19(1):13.

15. Thomas D. Gene-environment-wide association studies: emerging approaches. Nature Reviews Genetics. 2010;11(4):259.
16. Williams CA, Dagli A, Battaglia A. Genetic disorders associated with macrocephaly. American journal of medical genetics Part A. $2008 ; 146(15): 2023-37$.

17. Moir HJ, Kemp R, Folkerts D, Spendiff O, Pavlidis C, Opara E. Genes and Elite Marathon Running Performance: A Systematic Review. Journal of sports science \& medicine 2019;18(3):559-68.

18. Schröder W, Klostermann A, Distl 0 . Candidate genes for physical performance in the horse. The Veterinary Journal 2011;190(1):39-48.

19. Bauman AE, Reis RS, Sallis JF, Wells JC, Loos RJ, Martin BW, Lancet Physical Activity Series Working Group. Correlates of physical activity: why are some people physically active and others not?. The lancet $2012 ; 380(9838): 258-71$.

20. MacArthur DG, North KN. Genes and human elite athletic performance. Human genetics 2005;116(5):331-9.

21. Zehsaz F, Safabakhsh AH, Farhangi N, Keynezhad N, Monfaredan A, Ghahramani M. Do ACE and CKMM gene variations have potent effects on physical performance in inactive male adolescents?. Molecular biology reports. 2019;46(2):1835-43.

22. Payne $J$ and Montgomery H. Angiotensinconverting enzyme and human physical performance. Equine and Comparative Exercise Physiology 2004;(4): 255-260.

23. Scott RA, Moran C, Wilson RH, Goodwin WH, Pitsiladis YP. Genetic influence on East African running success. Equine and Comparative Exercise Physiology. 2004;1(4):273-80.

24. Woods DR, Brull D and Montgomery HE. Endurance and the ACE I/D polymorphism. Science Progress 2000;83: 317-336. 